\title{
Identification and Quantification of the Main Active Anticancer Alkaloids from the Root of Glaucium flavum
}

\section{Lamine Bournine ${ }^{1,2,3}$, Sihem Bensalem ${ }^{1}$, Jean-Noël Wauters ${ }^{3}$, Mokrane Iguer-Ouada ${ }^{4}$, Fadila Maiza-Benabdesselam ${ }^{1}$, Fatiha Bedjou ${ }^{1}$, Vincent Castronovo ${ }^{2}$, Akeila Bellahcène ${ }^{2}$, Monique Tits ${ }^{3}$ and Michel Frédérich ${ }^{3}$ *}

1 Plant Biotechnology and Ethnobotany Laboratory, Faculty of Natural Sciences and Life,

University of Bejaia, Targa Ouzemour, 06000 Bejaia, Algeria;

E-Mails: lbournine@student.ulg.ac.be (L.B.); bensalemsihem06@yahoo.fr (S.B.);

fadilamaiza@yahoo.fr (F.M.-B.); fatihabedjou@yahoo.fr (F.B.)

2 Metastasis Research Laboratory, GIGA-Cancer, University of Liege,

Institute of Pathology B23 avenue de l'Hôpital 3, B-4000 Liege, Belgium;

E-Mails: vcastronovo@ulg.ac.be (V.C.); a.bellahcene@ulg.ac.be (A.B.)

3 Pharmacognosy Laboratory, CIRM, University of Liege, Institute of Pharmacy B36 avenue de l'Hôpital 1, B-4000 Liege, Belgium; E-Mails: jean-noel.wauters@ulg.ac.be (J.-N.W.); m.tits@ulg.ac.be (M.T.)

Marine Ecosystems and Aquacultural Laboratory, Faculty of Natural Sciences and Life,

University of Bejaia, Targa Ouzemour, 06000 Bejaia, Algeria; E-Mail: imokrane@ gmail.com (M.I.-O.)

* Author to whom correspondence should be addressed; E-Mail: M.Frederich@ulg.ac.be;

Tel.: +32-4-3664-330; Fax: +32-4-3664-332.

Received: 10 October 2013; in revised form: 18 November 2013 / Accepted: 20 November 2013 /

Published: 2 December 2013

Abstract: Glaucium flavum is used in Algerian folk medicine to remove warts (benign tumors). Its local appellations are Cheqiq el-asfar and Qarn el-djedyane. We have recently reported the anti-tumoral activity of Glaucium flavum root alkaloid extract against human cancer cells, in vitro and in vivo. The principal identified alkaloid in the extract was protopine. This study aims to determine which component(s) of Glaucium flavum root extract might possess potent antitumor activity on human cancer cells. Quantitative estimation of Glaucium flavum alkaloids was realized by HPLC-DAD. Glaucium flavum effect on human normal and cancer cell viability was determined using WST-1 assay. Quantification of alkaloids in Glaucium flavum revealed that the dried root part contained $0.84 \%$ of protopine and $0.07 \%$ of bocconoline $(w / w)$, while the dried aerial part contained only $0.08 \%$ of protopine, glaucine as the main alkaloid, and no bocconoline. In vitro 
evaluation of the growth inhibitory activity on breast cancer and normal cells demonstrated that purified protopine did not reproduce the full cytotoxic activity of the alkaloid root extract on cancer cell lines. On the other hand, bocconoline inhibited strongly the viability of cancer cells with an $I C_{50}$ of $7.8 \mu \mathrm{M}$ and only a low cytotoxic effect was observed against normal human cells. Our results showed for the first time that protopine is the major root alkaloid of Glaucium flavum. Finally, we are the first to demonstrate a specific anticancer effect of Glaucium flavum root extract against breast cancer cells, which can be attributed, at least in part, to bocconoline.

Keywords: Glaucium flavum; Papaveraceae; HPLC-DAD; protopine; bocconoline; anti-cancer

\section{Introduction}

Glaucium flavum (yellow hornpoppy) belongs to the family of Papaveraceae. G. flavum is an almost glabrous perennial herb with large yellow flowers and elongated capsule [1]. It spontaneously occurs along the entire Mediterranean coast (sandy land). It is also present in the Atlantic coast of Europe [2].

G. flavum is commonly referred as Chelidonium due to its morphological resemblance to Chelidonium majus. In France, this plant has synonyms: Chelidonium fulvum Poir. or Chelidonium glaucium L. [3]. G. flavum is used in different remedies depending on the regions. The powder seeds have been used as laxative [4]. The infusion of aerial part of G. flavum was used as antitussive [5]. The latex of the stem of this plant was used as antiseptic, cicatrizing agent and to heal minor sores and wounds [5]. In Algeria, this plant was used as detersive, hypotensive, and pectoral. The latex was employed locally to remove warts [6]. It has been demonstrated that the aerial part of G. flavum presented pharmacological activities including anti-inflammatory, analgesic and antipyretic [7], hypoglycemic [8], and antioxidant activity [9].

In a previous work, we studied the antitumor activity of G. flavum in vitro and in vivo [10]. We performed a preliminary cytotoxic screening in vitro towards human breast cancer cells of different extracts of G. flavum. The alkaloid root extract showed the most potent effect and using HPLC analysis, we demonstrated the presence of protopine as the major alkaloid in this extract. It has been reported earlier that the aerial part of this plant is very rich in isoquinoline alkaloids, principally the aporphine base $S$-(+)-glaucine $\left(\mathrm{C}_{21} \mathrm{H}_{25} \mathrm{NO}_{4}\right)$ [11,12]. The amount of glaucine in yellow horn poppy grass has been previously determined by HPLC analysis [13]. There are however no reports comparing the analysis of the chemical composition and relative distribution of alkaloids in the root and aerial parts of the plant. In addition, to our knowledge, the analytical reports on roots are limited and poor data about the alkaloids composition of this plant part are available. Here, a comparative phytochemical study between the alkaloid extracts of aerial part and root of G. flavum was performed. In order to quantify the major active alkaloids beside the dry weight of the powder of aerial and root parts, HPLC quantification was monitored.

Hence, the present work therefore aims to identify and to quantify the compound(s) that are responsible of the antitumor effect of $G$. flavum root alkaloid extract, to perform a comparative 
phytochemical study between roots and aerial parts and to determine the occurrence of the main active alkaloids in these two parts of the plant.

\section{Results and Discussion}

A preliminary phytochemical screening of G. flavum alkaloid root extract was realized by TLC and by comparison with reference standards. This analysis revealed the presence of alkaloids in the plant, using the Dragendorff reagent (data not shown). The HPLC-DAD analysis showed that alkaloids from the alkaloidic root extract could be divided in two main groups (Figure 1A). The first group was eluted with an approximative retention time of $35 \mathrm{~min}$. It contained protopine as major compound (Peak 2), magnoflorine (Peak 1), chelidonine (Peak 3), sanguinarine (Peak 4), and chelerythrine (Peak 5) (Figure 2). These compounds were identified by comparing their retention times, their UV and MS spectra with those of authentic standards injected under the same conditions.

Figure 1. HPLC-DAD of alkaloidic extract (A) and methanolic extraction of the dry powder (B) of root of $G$. flavum at diode array UV-detection $(\lambda=290 \mathrm{~nm})$. Peak identification: (1) magnoflorine, (2) protopine as major compound, (3) chelidonine, (4) sanguinarine, (5) chelerythrine, (6) bocconoline.

A

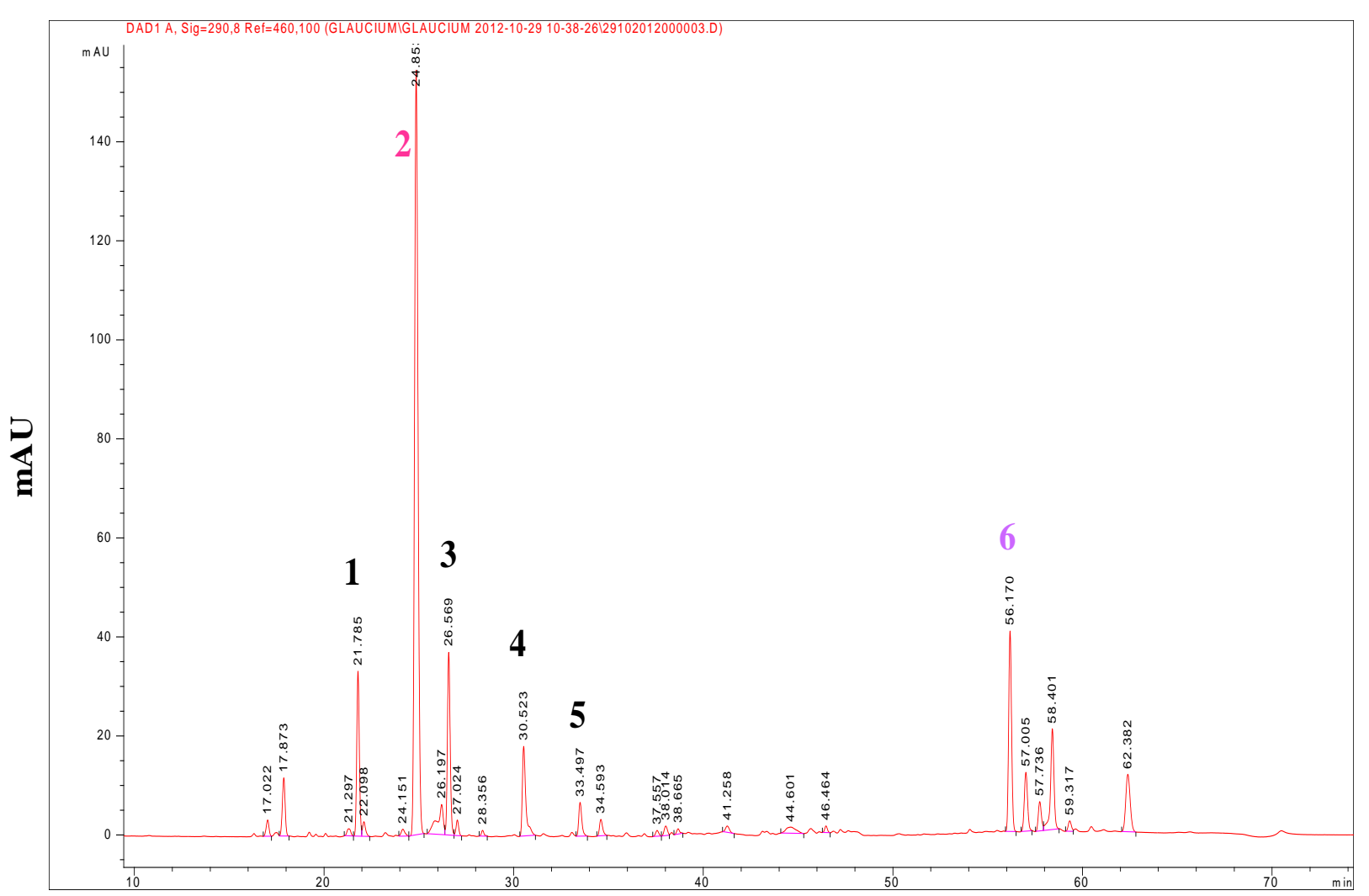

Retention time (min) 
Figure 1. Cont.

B

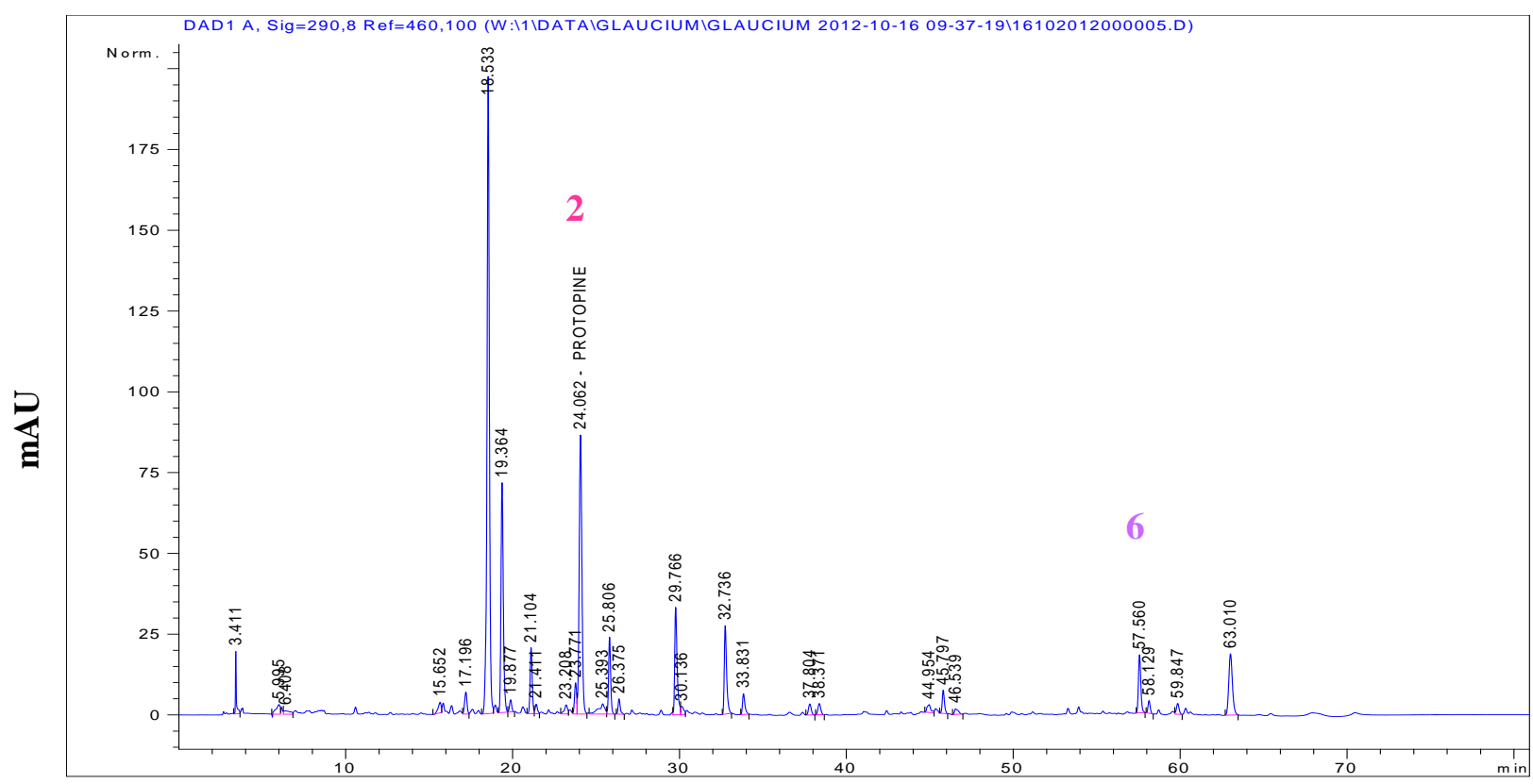

Retention time (min)

Figure 2. Molecular structure of identified alkaloids in the root alkaloid extract.

1. Magnoflorine Type<smiles>COc1ccc2c(c1O)-c1c(O)c(OC)cc3c1C(C2)N(C)CC3</smiles>

3. Chelidonine<smiles>CN1Cc2c(ccc3c2OCO3)C2C1c1cc3c(cc1C[C@@H]2O)OCO3</smiles>

5. Chelerythrine<smiles>COc1ccc2c(c[n+](C)c3c4cc5c(cc4ccc23)OCO5)c1OC</smiles>

2. Protopine<smiles>CN1CCc2cc3c(cc2C(=O)Cc2ccc4c(c2C1)OCO4)OCO3</smiles>

4. Sanguinarine<smiles>C[n+]1cc2c3c(ccc2c2ccc4cc5c(cc4c21)OCO5)OCO3</smiles>

6. Bocconoline<smiles>COc1ccc2c(c1OC)C(CO)N(C)c1c-2ccc2cc3c(cc12)OCO3</smiles> 
Crystals of protopine were recovered by simple precipitation from the alkaloidic root extract in methanol. To identify this compound we used LC-MS in positive mode. The ESI-MS spectrum of this compound was found at $\mathrm{m} / \mathrm{z} 354.13$, which corresponded to the molecular mass of protopine. We confirmed this result by comparison of HPLC-DAD analysis of the obtained crystals and protopine standard (same retention time and UV spectra, data not shown). The qualitative and quantitative profiles of aporphinic alkaloids of G. flavum were completely different depending on the part of the plant. Quantitative determination of protopine in roots "alkaloid extract and dry powder" (Figure 1A,B) and in aerial part "alkaloid extract and dry powder" (Figure 3A,B) were carried out using HPLC-DAD.

Figure 3. Representative HPLC-DAD chromatograms of alkaloidic extract (A) and methanolic extraction of the dry powder (B) of aerial part of G. flavum. Peaks (2) and (6) correspond to quantified compounds in plant (protopine and bocconoline, respectively). The major peak showed in section (A) and (B) correspond to glaucine.

A

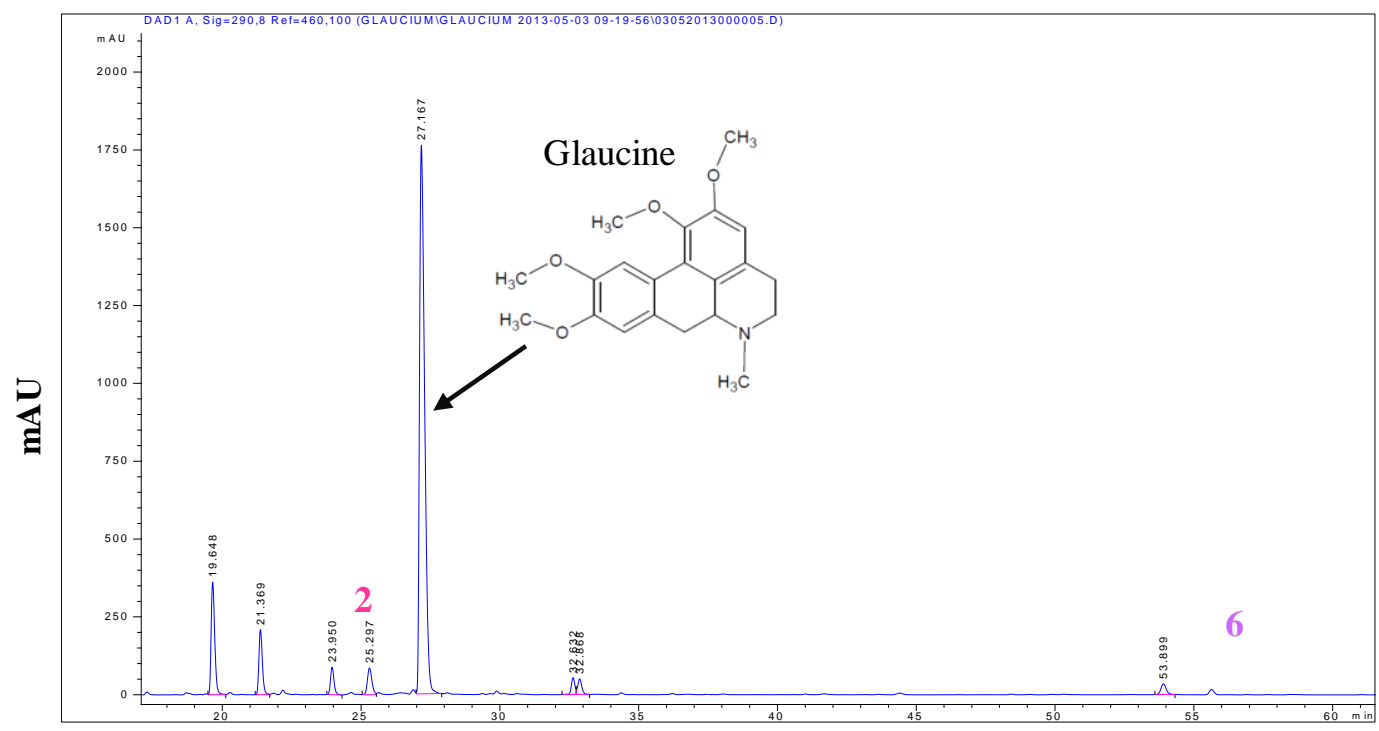

B

Retention time (min)

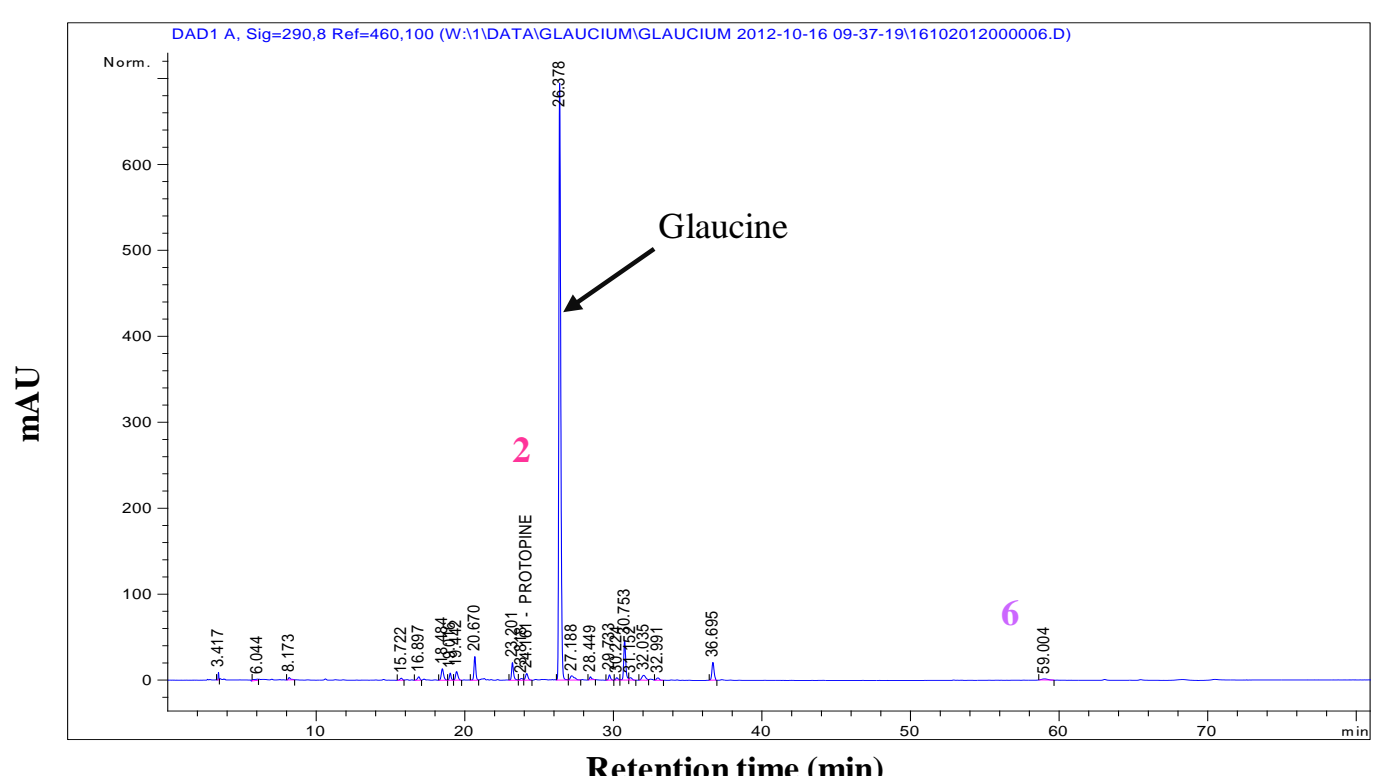

Retention time (min) 
The root part of G. flavum mainly contained protopine that reached a very high amount of $0.84 \%$ (in dried root) (Table 1). The concentration of the aporphinic alkaloids found in roots of Algerian G. flavum was higher than that reported previously in Brno, Czech Republic [14]. These differences and discrepancies could be explained by differences in method of analysis or geographical origin and the stage of development of the plant [15]. The aerial part of G. flavum had low levels of protopine $0.08 \%$ (in dried aerial part) while it contained a very high proportion of glaucine. The high concentration of glaucine in aerial part of G. flavum has been previously established [13]. Alkaloidic extracts of root and aerial part contained $41.60 \%$ and $3.86 \%$ of protopine $(w / w)$, respectively (Table 1 ).

Table 1. Content (\%) of alkaloids 2 (protopine) and $\mathbf{6}$ (bocconoline) in G. flavum root and aerial parts.

\begin{tabular}{ccccc}
\hline Plant part & Root $*$ & Aerial part $*$ & Root alkaloid extract & Aerial part alkaloid extract \\
\hline Protopine & $0.84 \%$ & $0.08 \%$ & $41.60 \%$ & $3.86 \%$ \\
Bocconoline & $0.07 \%$ & - & $4.43 \%$ & - \\
\hline
\end{tabular}

(*) Amount in the dried plant was calculated using a methanolic extraction; (-) Not detectable.

The effect of protopine on the viability of human breast cancer cells MDA-MB-231 and normal human cells (HUVEC) was evaluated in vitro. Protopine demonstrated a moderate cytotoxic effect against breast cancer cell lines and did not affect the growth of normal cells (Figure 4B). The inhibitory effect on cancer cell viability has been observed in the range of 20-40 $\mu \mathrm{M}$. To our knowledge, only one study has reported the anti-proliferative effect of protopine using human prostate cancer cells [16]. These authors used concentrations of protopine ranging from 3 to $50 \mu \mathrm{M}$ to evaluate the effect of protopine on cancer cell viability. They demonstrated that protopine caused tubulin polymerization, leading to $\mathrm{Cdk} 1$ activation and mitotic arrest of the cell cycle that finally triggered mitochondria-mediated apoptotic signaling pathwAays [16]. Interestingly, we noticed that protopine used over $40 \mu \mathrm{M}$ appeared to promote cancer cell viability (Figure 4B). Based on the available literature, at least two mechanisms can be proposed to explain this result. A previous study reported that protopine exerted a cellular protective effect on hydrogen peroxide-induced apoptosis and oxidative stress in rat tumor cells [17]. In this study, the authors proposed that the protective effect of protopine could be attributed firstly, to an anti-apoptotic mechanism including: (a) a decrease of the intracellular $\mathrm{Ca}^{2+}$ content via directly blocking $\mathrm{Ca}^{2+}$ channels; (b) an increase of the mitochondrial membrane potential, and (c) an inhibition of caspase-3 expression; and secondly, through an antioxidant mechanism by enhancing the activity of the intracellular antioxidant enzymatic system. These authors indicated that this antioxidant ability may be attributed to pyrocatechol, a metabolite of protopine [17]. In light of these results, we propose that protopine at high concentration may promote the viability of human breast cancer cells through similar anti-apoptotic and/or an antioxidant mechanisms. Ongoing studies will help to determine the precise mechanism(s) of this potential dual role of protopine on cancer cell survival and growth. Furthermore, the determination of the precise cut off value and concentration limits of protopine will be necessary before its use as an anti-neoplastic agent. 
Figure 4. In vitro growth inhibitory activity of G. flavum alkaloids root extract (A), protopine (B), and bocconoline (C) against malignant human breast cancer cells (MDA-MB-231) and Human Umbilical Vein Endothelial Cells (HUVEC). Cells were treated with DMSO vehicle or the indicated concentrations of G. flavum alkaloids root extract, protopine and bocconoline for $24 \mathrm{~h}$. Cell viability was determined using WST-1 assay and expressed as means \pm S.E.M of three separate experiments $(n=3)$. $* p<0.05 ; * * p<0.01 ; * * * p<0.001$ compared with control group.

A

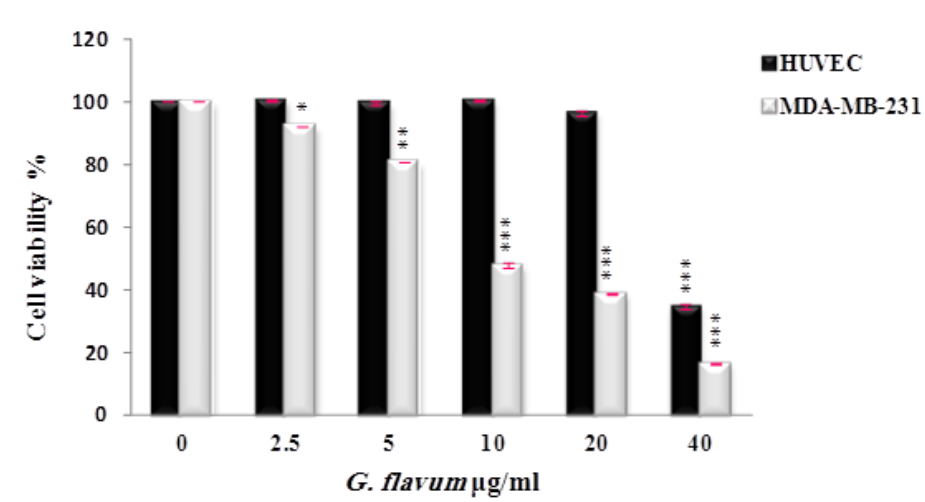

B

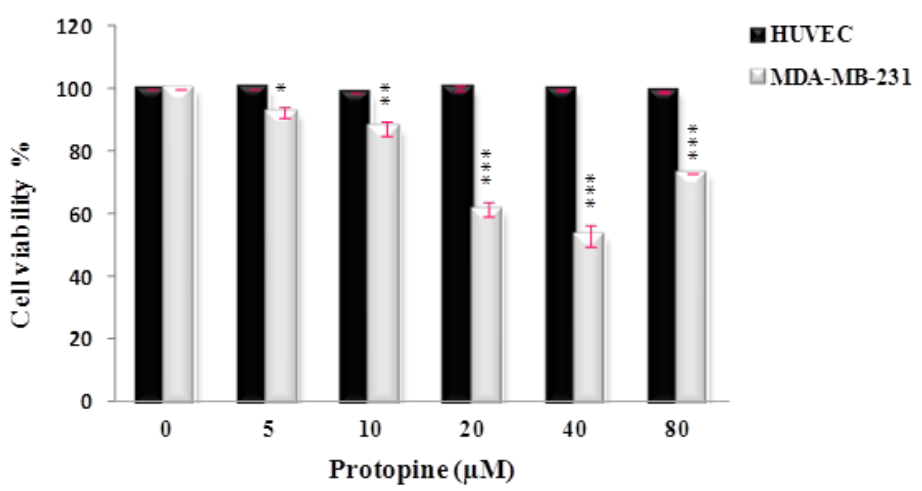

C

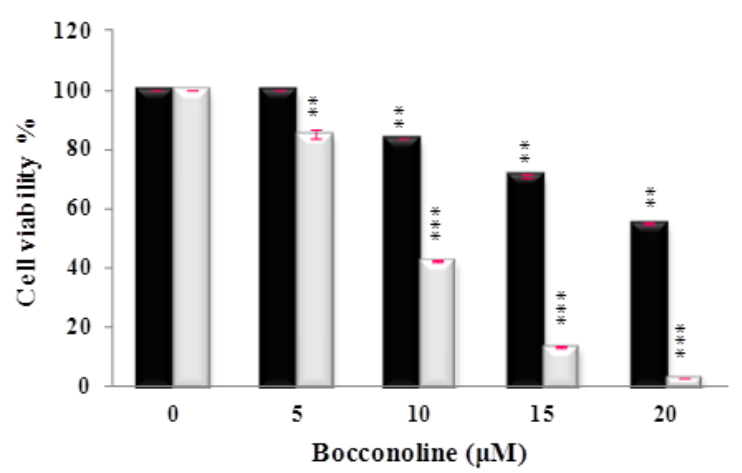

These findings led us to search for another major compound, which could explain the global antitumoral effect of G. flavum alkaloid extract. Thus, we decided to isolate and identify the major compound of the second group of alkaloids of the root extract using preparative HPLC. This group of compounds was eluted at a retention time close to $60 \mathrm{~min}$ in the HPLC separation; it contained one major compound (Peak 6) (Figure 1A). This compound was eluted at $56.61 \mathrm{~min}$. Its molecular formula was determined to be $\mathrm{C}_{22} \mathrm{H}_{21} \mathrm{NO}_{5}$ by HR-ESIMS analysis $\left([\mathrm{M}+\mathrm{Na}]^{+}\right.$at $\left.\mathrm{m} / \mathrm{z}, 380.15\right)$. The identification of compound (6) was determined by NMR analysis $\left({ }^{1} \mathrm{H},{ }^{13} \mathrm{C}\right.$, COSY, HSQC and HMBC). The 2D NMR has never been recorded previously and is presented here for the first time (Supplementary 
Figures 1-5). The compound (6) was identified as bocconoline. The structure of bocconoline is presented in Figure 2. Previously, the ${ }^{1} \mathrm{H}$ and ${ }^{13} \mathrm{C}$ NMR data for bocconoline were reported in Rutaceae (bark of Zanthoxylum davyi and Fagara mayu) $[18,19]$. Hence, the quantitative estimation of bocconoline was approached in alkaloid extracts and in dry powders of root and aerial parts of G. flavum using HPLC-DAD (Figure 3A,B and Figure 1A,B). We determined that the underground part of G. flavum contained bocconoline at a concentration of $0.07 \%$ (in dried root), and at a concentration of $4.43 \%$ $(w / w)$ in alkaloid extract. This compound was completely absent from the dry powder and alkaloid extract of the aerial part (Table 1).

The potential cytotoxic effect of bocconoline on cancer cells has never been investigated. The viability test showed that it has a potent antiproliferative activity against MDA-MB-231 human breast cancer cells in a dose-dependent manner (Figure $4 \mathrm{C}$ ), with an $I C_{50}$ value of $7.8 \mu \mathrm{M}$. In this range of concentrations, bocconoline did not affect significantly the growth of normal human cells (HUVEC). This profile is similar to G. flavum alkaloid root extract, which exhibited a selective effect toward cancer cells without affecting normal cells. Altogether our data suggest that bocconoline is mainly responsible of the anti-proliferative effect of G. flavum alkaloid root extract (Figure 4A-C). More studies are needed to determine the molecular mechanism of action of bocconoline and to evaluate its anticancer activity in vivo.

\section{Experimental Section}

\subsection{Standards and Chemicals}

Protopine, chelerythrine, and chelidonine were obtained from Extrasynthese (Lyon, France) and sanguinarine was purchased from Sigma-Aldrich (St. Louis, MO, USA). All references had a purity $\geq 98.0 \%$ by HPLC-DAD. HPLC grade acetonitrile and methanol were purchased from Merck (Darmstadt, Germany). Trifluoroacetic acid (TFA) of HPLC analytical-grade was purchased from Sigma-Aldrich (St. Louis, MO, USA). The ultra pure water used for the HPLC analysis was obtained from a Millipore system (Milli-Q RG) (Millipore, Molsheim, France). All other solvents were of analytical grade and were purchased from Merck (Darmstadt, Germany).

\subsection{Instrumentations}

Chromatographic quantification was performed using an Agilent 1100 HPLC Series system (Agilent, Santa Clara, CA, USA) consisting of a degasser (G1379A), a high-pressure quaternary pump (G1311A), an autosampler (G1313A), a thermostatic compartment (G1316A), and a diode array detector (G1315A). Preparative High Performance Liquid Chromatography (Varian System) is consisting of a high-pressure binary pump (PrepStar), a diode array detector (ProStar), and an automatic fraction collector (440-LC). To determine the structure of isolated compounds we used various spectroscopic techniques. NMR spectra were recorded in $\mathrm{CDCl}_{3}$ using a Bruker Avance II $500 \mathrm{MHz}$ spectrometer (Messtechnik GmbH, Karlsruhe, Germany) equipped with a cryoprobe and using TMS as the internal reference. Mass spectrometry (MS) was performed with a micromass ESI-Q-TOF II instrument (supplied by Waters, Milford, MA, USA) using ESI-ionization in positive mode. The identity of the purified compounds was assessed by comparison of their NMR and MS data with data from the 
literature. The analysis of extract and isolated compounds were conducted using thin layer chromatography precoated Si gel F254 (Merck, 1.05735) plates.

\subsection{Plant Material}

The aerial parts and roots of G. flavum were collected in the littoral area in Tichy, province of Bejaia (Algeria), in June 2010, during the flowering period. These samples were authenticated by the botanists of University of Bejaia. A voucher specimen Nr 2011/0614 was left in the herbarium of the Laboratory of Pharmacognosy of University of Liege. The plant materials were cleaned and air-dried at room temperature. Both parts were ground to a fine powder and passed through a 63 mesh sieve, to provide homogeneous powder for the analysis. Powdered materials were maintained at room temperature, and protected from light until required for analyses.

\subsection{Extraction}

\subsubsection{Alkaloid Extract}

The extraction of alkaloids from G. flavum was carried out as following: the powdered root (10 g) was extracted with methanol $(100 \mathrm{~mL})$ using soxhlet apparatus. Methanol was evaporated under reduced pressure and the residue was taken up in $2 \%$ hydrochloric acid $(50 \mathrm{~mL})$, and then filtered through GHP $0.45 \mu \mathrm{m}$ filter (Waters Cooperation, Milford, MA, USA). The filtrate was adjusted to $\mathrm{pH} 8$ with aqueous ammonia and extracted three times with dichloromethane $(25 \mathrm{~mL})$. The resulting extract was dried over $\mathrm{MgSO}_{4}$ and the solvent evaporated to obtain the crude alkaloidic extract (0.2 g) [20].

\subsubsection{Methanolic Extraction}

The powdered aerial and root parts of G. flavum $(1 \mathrm{~g})$ were percolated with methanol $(100 \mathrm{~mL})$. The solution was filtered (membrane filter $0.45 \mu \mathrm{m}$ ), giving the sample before HPLC injection for the quantification of the main active alkaloids in the dry powder of the root and aerial part of G. flavum.

\subsection{HPLC-DAD Analysis and Quantification of Protopine and Bocconoline in G. flavum Extracts}

\subsubsection{HPLC Conditions}

The separation of $G$. flavum alkaloids was carried out using a Polaris Amide $\mathrm{C}_{18}$ Column $\left(250 \times 4.6 \mathrm{~mm}\right.$ i.d., $5 \mu \mathrm{m}$ particle, Varian, Palo Alto, CA, USA), which was maintained at $25{ }^{\circ} \mathrm{C}$. The mobile phase was composed of a gradient of solution A (trifluoroacetic acid $0.05 \%$ in water) and solution $\mathrm{B}$ (acetonitrile) programmed as follows: equilibration time $15 \mathrm{~min}$ at $100 \% \mathrm{~A}$ and linear gradient elution: $0 \min 100 \% \mathrm{~A} ; 1 \min 97 \% \mathrm{~A} ; 45 \min 60 \% \mathrm{~A} ; 55 \min 40 \% \mathrm{~A} ; 65 \min 40 \% \mathrm{~A}$ and $66 \mathrm{~min} 100 \% \mathrm{~A}$. The flow rate was $1 \mathrm{~mL} / \mathrm{min}$ and the injection volume was $10 \mu \mathrm{L}$. The run time of each analysis was $80 \mathrm{~min}$. Spectral data from all peaks were recorded in the range of $200-400 \mathrm{~nm}$, and chromatograms were recorded at $290 \mathrm{~nm}$. Protopine was isolated and identified as described previously [10]. The Agilent ChemStation (vA09.03) and DataAnalysis (v5.3) software were used for the acquisition and analysis of chromatographic data. Bocconoline was isolated from the alkaloids root extract of G. flavum. It was fractionated by PrepHPLC on a Luna PFP (pentafluorophenyl) column 
$\left(250 \times 4.6 \mathrm{~mm}, 5 \mu \mathrm{m}\right.$, phenomenex $\left.{ }^{\circledR}\right)$. A total of $376 \mathrm{mg}$ of the dichloromethane extract were dissolved in methanol $(7 \mathrm{~mL})$ and filtered through an Acrodisc PSF GXF/GHP $0.45 \mu \mathrm{m}$ filter and injected in PrepHPLC. The mobile phase consisted of TFA $0.05 \%$ (A) and methanol (B), which was applied in the following gradient elution: 0 min $80 \% \mathrm{~A} ; 45 \mathrm{~min} 20 \% \mathrm{~A}$ and $80 \mathrm{~min} 0 \% \mathrm{~A}$. Flow rate was $25 \mathrm{~mL} / \mathrm{min}$. The software used for the acquisition and analysis of chromatographic data in PrepHPLC was the Modular HPLC System Galaxie. The isolated compound (bocconoline) was identified by MS and ${ }^{1} \mathrm{H}$, ${ }^{13} \mathrm{C}$ NMR, COSY ${ }^{1} \mathrm{H}-{ }^{1} \mathrm{H}, \mathrm{HSQC}, \mathrm{HMBC}$.

\subsubsection{Preparation of Standard Solutions}

Standard solutions were prepared in methanol for protopine $(4-16 \mathrm{mg} / 100 \mathrm{~mL})$ and for bocconoline $(0.65-3.25 \mathrm{mg} / 100 \mathrm{~mL})$. The solution was filtered through a $0.45 \mu \mathrm{m}$ membrane filter disc before HPLC injection. The peak area of protopine and bocconoline were plotted against the concentration to obtain the calibration graph. A regression analysis was realized and the correlation coefficients were calculated (protopine $r^{2}>0.99996$ and bocconoline $r^{2}>0.99983$ ).

\subsection{Cell Viability Inhibition}

\subsubsection{Cell Lines}

Human Umbilical Vein Endothelial Cells (HUVEC) were isolated and maintained in culture as described previously [21,22]. Human breast cancer cells MDA-MB-231 (HTB-26, ATCC) were grown in Dulbecco's Modified Eagle's Medium (DMEM), supplemented with 10\% of fetal bovine serum and $1 \% \mathrm{~L}$-glutamine. All the cells were cultured at $37{ }^{\circ} \mathrm{C}$ in a humidified atmosphere and $5 \% \mathrm{CO}_{2}$.

\subsubsection{Cell Viability Analysis}

Cell viability was determined using the cell proliferation reagent WST-1 assay according to the manufacturer's instructions (Roche, Basel, Switzerland). All analyzed cells were seeded to obtain 50\% of confluence after $24 \mathrm{~h}$ of incubation in 96-well plates and then treated with serial dilutions of isolated compounds: bocconoline and protopine (0-20 and 0-80 $\mu \mathrm{M}$, respectively). Cells were then incubated with WST-1 reagent for $4 \mathrm{~h}$. After this incubation period, the formazan dye formed was quantified with a scanning multi-well spectrophotometer at $450 \mathrm{~nm}$. The measured absorbance directly correlates to the number of viable cells. Percentages of cell survival were calculated as follows:

$\%$ cell survival $=($ absorbance of treated cells/absorbance of cells with vehicle solvent $) \times 100$

The half inhibitory concentration $\left(I C_{50}\right)$ was calculated from the dose-response curve obtained by plotting the percentage of cell survival versus the concentration of compounds used.

\subsection{Statistical Analysis}

Results are expressed as mean \pm S.E.M. of at least three independent experiments. Student's $t$-test was used to compare the difference between each treated group to the control. $p$-Values $<0.05$ were considered as significant. 


\section{Conclusions}

We demonstrate here for the first time that protopine is the major alkaloid in G. flavum root extract and we confirmed that glaucine is the major compound in the aerial part as described in the literature. High-performance liquid chromatography (HPLC-DAD) has been used to quantify active alkaloids in G. flavum aerial part and root extracts. We showed that the chromatogram of roots contained two main groups of alkaloids. The first group contained protopine as the major compound, with a concentration of $41.6 \%(w / w)$ in the alkaloid root extract. The cytotoxic effect of this alkaloid on viability of breast cancer was evaluated and we have observed no cytotoxic effect against human normal cells. The main alkaloid of the second group was identified as bocconoline $(4.43 \% \mathrm{w} / \mathrm{w})$. The cytotoxic effect of this alkaloid against human breast cancer MDA-MB-231 cells was dose dependent with an $I C_{50}=7.8 \mu \mathrm{M}$ and only low cytotoxicity was observed toward normal cells. These findings led us to suggest that the specific anticancer effects of G. flavum extract could be attributed, at least in part, to bocconoline, which is the second major alkaloid of the root. Further investigations are needed to confirm the pharmacological activity of the major alkaloids present in G. flavum extract in animal models, to assess the safe use of the plant, which could lead to the potential development of an effective cancer chemotherapy agent.

\section{Acknowledgments}

L.B received an Averroes study grant (Erasmus Mundus program, University A. Mira of Bejaia and University of Liege). A.B is a senior research associate from the Belgium National Fund for Scientific Research (FNRS). The authors acknowledge the expert technical guidance of Delphine Etienne. We thank JN Waters for his technical assistance and JC van Heugen for recording MS spectra. This work was partly supported by the FNRS grant $\mathrm{N}^{\circ} 3.4533 .10$.

\section{Conflicts of Interest}

The authors declare no conflict of interest.

\section{References}

1. Quézel, P.; Santa, S. Nouvelle Flore D’Algérie et des Régions Désertiques Méridionales; Centre National de la Recherche Scientifique: Paris, France, 1962; Volume 1.

2. Schreter, G.K. Yellow horned poppy: A new medicinal plant. Farmatsevticheskii Zhurnal 1976, 10, 77-83.

3. Julve, P. Baseflor: Index botanique, écologique et chorologique de la flore de France. Available online: http://www.tela-botanica.org/bdtfx-nn-30228 (accessed on 23 September 2013).

4. Safa, O.; Soltanipoor, M.A.; Rastegar, S.; Kazemi, M.; Dehkordi, K.N.; Ghannadi, A. An ethnobotanical survey on hormozgan province, Iran. Avicenna J. Phytomed. 2013, 3, 64-81.

5. Leporatti, M.L.; Ivancheva, S. Preliminary comparative analysis of medicinal plants used in the traditional medicine of Bulgaria and Italy. J. Ethnopharmacol. 2003, 87, 123-142.

6. Baba-aissa, F. Encyclopedie des plante utiles: Flore d'Algérie et du Maghreb, substances végétales d'Afrique d'Orient et d'Occident; Édas, librairie moderne: Rouiba, Algérie, 2000. 
7. Pinto, L.; Borrelli, F.; Bombardelli, E.; Cristoni, A.; Capasso, F. Anti-inflammatory, analgesic and antipyretic effects of glaucine in rats and mice. Pharm. Pharmacol. Commun. 1998, 4, 502-505.

8. Cabo, J.; Cabo, P.; Jimenez, J.; Zarzuelo, A. Glaucium flavum Crantz. Part v: Hypoglycemic activity of the aqueous extract. Phytother. Res. 2006, 2, 198-200.

9. Tawaha, K.; Alali, F.; Gharaibeh, M.; Mohammad, M.; Elelimat, T. Antioxidant activity and total phenolic content of selected Jordanian plant species. Food Chem. 2007, 104, 1372-1378.

10. Bournine, L.; Bensalem, S.; Peixoto, P.; Gonzalez, A.; Maiza-Benabdesselam, F.; Bedjou, F.; Wauters, J.N.; Tits, M.; Frederich, M.; Castronovo, V.; et al. Revealing the anti-tumoral effect of Algerian Glaucium flavum roots against human cancer cells. Phytomedicine 2013, 20, 1211-1218.

11. Israilov, I.A.; Karimova, S.U.; Yunusov, M.S. Glaucium alkaloids. Chem. Nat. Comp. 1979, 15, 103-113.

12. Daskalova, E.; Iskrenova, E.; Kiryakov, H.G.; Evstatieva, L. Minor alkaloids of Glaucium flavum. Phytochemistry 1988, 27, 953-955.

13. Lapa, G.B.; Sheichenko, O.P.; Serezhechkin, A.G.; Tolkachev, O.N. HPLC determination of glaucine in yellow horn poppy grass (Glaucium flavum Crantz.). Pharm. Chem. J. 2004, 38, 32-33.

14. Novák, V.; Slavík, J. Further alkaloids from Glaucium flavum CR. Collect. Czech. Chem. Commun. 1974, 39, 3352-3356.

15. Petitto, V.; Serafini, M.; Gallo, F.R.; Multari, G.; Nicoletti, M. Alkaloids from Glaucium flavum from Sardinia. Nat. Prod. Res. 2010, 24, 1033-1035.

16. Chen, C.H.; Liao, C.H.; Chang, Y.L.; Guh, J.H.; Pan, S.L.; Teng, C.M. Protopine, a novel microtubule-stabilizing agent, causes mitotic arrest and apoptotic cell death in human hormone-refractory prostate cancer cell lines. Cancer Lett. 2012, 315, 1-11.

17. Xiao, X.; Liu, J.; Hu, J.; Zhu, X.; Yang, H.; Wang, C.; Zhang, Y. Protective effects of protopine on hydrogen peroxide-induced oxidative injury of $\mathrm{PC} 12$ cells via $\mathrm{Ca}^{2+}$ antagonism and antioxidant mechanisms. Eur. J. Pharmacol. 2008, 591, 21-27.

18. Tarus, P.K.; Coombes, P.H.; Crouch, N.R.; Mulholland, D.A. Benzo[c]phenanthridine alkaloids from stem bark of the Forest Knobwood, Zanthoxylum davyi (Rutaceae). S. Afr. J. Bot. 2006, 72, 555-558.

19. Assem, E.M.; Benages, I.A.; Albonico, S.M. Further alkaloids from bark of Fagara mayu. Planta Medica 1983, 48, 77-80.

20. Suau, R.; Cabezudo, B.; Rico, R.; Nájera, F.; López-Romero, J.M.; Cuevas, A. Phytochemical variations within populations of Platycapnos saxicola Willk. Biochem. Syst. Ecol. 2004, 32, 565-572.

21. Jaffe, E.A.; Nachman, R.L.; Becker, C.G.; Minick, C.R. Culture of Human endothelial cells derived from umbilical veins identification by morphologic and immunologic criteria. J. Clin. Investig. 1973, 52, 2745-2756.

22. Pirotte, S.; Lamour, V.; Lambert, V.; Alvarez Gonzalez, M.L.; Ormenese, S.; Noel, A.; Mottet, D.; Castronovo, V.; Bellahcene, A. Dentin matrix protein 1 induces membrane expression of VE-cadherin on endothelial cells and inhibits VEGF-induced angiogenesis by blocking VEGFR-2 phosphorylation. Blood 2011, 117, 2515-2526.

(C) 2013 by the authors; licensee MDPI, Basel, Switzerland. This article is an open access article distributed under the terms and conditions of the Creative Commons Attribution license (http://creativecommons.org/licenses/by/3.0/). 